Trauma Surgery \& Acute Care Open

\title{
Mass casualty events: what to do as the dust settles?
}

\author{
Rachel M Russo, ${ }^{1}$ Joseph M Galante, ${ }^{1}$ John B Holcomb, ${ }^{2}$ Warren Dorlac, ${ }^{3}$ \\ Jason Brocker, ${ }_{1}^{4}$ David R King, ${ }^{5}$ M Margaret Knudson, ${ }^{6}$ Thomas M Scalea, ${ }^{4}$ \\ Michael L Cheatham, ${ }^{7}$ Raymond Fang ${ }^{8}$
}

\begin{abstract}
'Department of Surgery, University of California Davis,

Sacramento, California, USA

'UT Health, Houston, Texas, USA

${ }^{3}$ Medical Center of the Rockies,

Denver, Colorado, USA

${ }^{4}$ University of Maryland,

Baltimore, Maryland, USA

${ }^{5}$ Massachusetts General

Hospital, Boston, Massachusetts, USA

${ }^{6}$ Department of Surgery, University of California, San

Francisco, California, USA ${ }^{7}$ Orlando Regional Medical Center, Orlando, Florida, USA

${ }^{8}$ Johns Hopkins University,

Baltimore, Maryland, USA
\end{abstract}

Correspondence to Dr Joseph M Galante, Department of Surgery, University of California Davis School of Medicine, Sacramento CA 95817, USA; jmgalante@ ucdavis.edu

Received 10 July 2018 Accepted 16 July 2018

(c) Author(s) (or their employer(s)) 2018. Re-use permitted under CC BY-NC. No commercial re-use. See rights and permissions. Published by BMJ.

To cite: Russo RM, Galante JM, Holcomb JB, et al. Trauma Surg Acute Care Open 2018;3:e00210.

\section{ABSTRACT}

Care during mass casualty events (MCE) has improved during the last 15 years. Military and civilian collaboration has led to partnerships which augment the response to MCE. Much has been written about strategies to deliver care during an MCE, but there is little about how to transition back to normal operations after an event. A panel discussion entitled The Day(s) After: Lessons Learned from Trauma Team Management in the Aftermath of an Unexpected Mass Casualty Event at the 76th Annual American Association for the Surgery of Trauma meeting on September 13, 2017 brought together a cadre of military and civilian surgeons with experience in MCEs. The events described were the First Battle of Mogadishu (1993), the Second Battle of Fallujah (2004), the Bagram Detention Center Rocket Attack (2014), the Boston Marathon Bombing (2013), the Asiana Flight 214 Plane Crash (2013), the Baltimore Riots (2015), and the Orlando Pulse Night Club Shooting (2016). This article focuses on the lessons learned from military and civilian surgeons in the days after MCEs.

\section{INTRODUCTION}

The last 15 years of war have advanced care after mass casualty events (MCEs), dramatically improving patient survival. ${ }^{1}$ As such, lessons borrowed from the military have been applied to domestic healthcare. Partnerships have formed, with a combined military-civilian response to Hurricane Harvey, a train derailment in Tacoma, Washington, and the Las Vegas massacre. ${ }^{23}$

To expand on this theme, the American Association for the Surgery of Trauma (AAST) assembled a cadre of military and civilian physicians with experience in mass casualty trauma care to facilitate domestic preparedness for the next MCE. The speakers described their experience dealing with multiple casualties and strategies to handle the aftermath after the initial surge as they transitioned their hospitals to normal operation. Whereas much has been written about delivering care during an MCE, the focus of this article is to highlight shared strategies to deal with the aftermath of MCEs. The content of this article is drawn from the lessons learned after MCEs in military and civilian healthcare settings.

\section{METHODS}

A qualitative theme array analysis was performed by two independent reviewers present for the panel discussion entitled The Day(s) After: Lessons Learned from Trauma Team Management in the Aftermath of an Unexpected Mass Casualty Event hosted by the Military Liaison Committee at the 76th Annual AAST meeting in Baltimore, Maryland, on September 13, 2017. Relevant themes were organized into categories. Areas of consensus were used to generate this article. The article was reviewed by the panelists to ensure their thoughts and descriptions were captured and depicted correctly.

\section{Event descriptions}

A summary of the MCEs described in the session can be found in table 1 .

The First Battle of Mogadishu, October 3-4, 1993 A US Army surgeon described his experience caring for injured soldiers during the First Battle of Mogadishu. In the events made famous by the book Black Hawk Down, 19 US soldiers were killed and 73 wounded in action in an overnight combat operation. ${ }^{4}$ With some personnel trapped by surrounding hostile combatants, medical care was initially delivered while under fire. Faced with several heavily injured soldiers and few resources, the panelist described lessons learned from simultaneously caring for patients and ensuring the safety of the healthcare team.

Operation Phantom Fury, the Second Battle of Fallujah, November 7-10, 2004

A US Air Force surgeon described caring for the injured transported to the theater evacuation hub during Operation Phantom Fury (OPF), the Second Battle of Fallujah, the bloodiest battle of the Iraq War. Coalition forces suffered 107 killed and 613 wounded in action over a period of 4 days. More than 200 required hospital treatment, with 191 operations performed.

\section{Bagram Detention Center Rocket Attack, October 31, 2014}

Another US Air Force surgeon described the events of October 31, 2014, in which 26 prisoners were injured in a rocket attack on Bagram detention facility. Healthcare providers were tasked with caring for detainees while under rocket attack. $\mathrm{He}$ described managing the logistical, ethical, and security concerns shared by his medical team as they cared for the injured.

\section{Boston Marathon Bombing, April 15, 2013}

A trauma surgeon at Massachusetts General Hospital (MGH) recounted delivering care to civilians dismembered when two homemade bombs 
Table 1 Description of mass casualty events presented at the panel discussion entitled The Day(s) After: Lessons Learned from Trauma Team Management in the Aftermath of an Unexpected Mass Casualty Event hosted by the Military Liaison Committee at the 76th Annual American Association for the Surgery of Trauma meeting in Baltimore, Maryland, on September 13, 2017

\begin{tabular}{llll}
\hline Event & Location & Date(s) & Military/Civilian \\
\hline The First Battle of Mogadishu & Mogadishu, Somalia & October 3-4, 1993 & Military \\
\hline Operation Phantom Fury, the Second Battle of Fallujah & Fallujah, Iraq & November 7-10, 2004 & Military \\
\hline Bagram Detention Center Rocket Attack & Bagram Air Base, Afghanistan & October 31, 2014 & Military \\
\hline Boston Marathon Bombing & Boston, Massachusetts & April 15, 2013 & Civilian \\
\hline Asiana Flight 214 Plane Crash & San Francisco, California & July 6, 2013 & Civilian \\
Baltimore Riots & Baltimore, Maryland & April 18-May 3, 2015 & Civilian \\
\hline Orlando Pulse Night Club & Orlando, Florida & June 12, 2016 & Civilian \\
\hline
\end{tabular}

were detonated near the finish line of the annual Boston Marathon, which killed 3 and injured 243. The panelist described facilitating care of the injured at an experienced trauma center having all hands on deck during change of shift.

\section{Asiana Flight 214 Plane Crash, July 6, 2013}

On July 6, 2013, Asiana Airlines Flight 214, a transpacific passenger flight carrying 307 individuals from Seoul, South Korea, crashed on final approach at the San Francisco International Airport. Three individuals were killed in the crash and 187 passengers were injured, 49 seriously. A trauma surgeon from the San Francisco General Hospital described the challenges of caring for a multitude of seriously injured, unidentified, non-English-speaking minors in the midst of international media attention.

\section{Baltimore Riots, April 18-May 3, 2015}

Following the death of Freddy Gray, a 25 -year-old African-American man who died while in police custody, a series of riots broke out in Baltimore, Maryland. A trauma surgeon at the University of Maryland's Shock Trauma Center described his experience caring for people injured in the riots as violence escalated in the streets around the hospital. The panelist discussed the challenges faced by healthcare providers sequestered at the hospital, separated from their families, for days during the pinnacle of riots.

\section{Orlando Pulse Night Club Shooting, June 12, 2016}

On June 12, 2016, a shooter killed 49 people and wounded 58 others in an attack inside the Pulse Night Club in Orlando, Florida. Only blocks away from Orlando Regional Medical Center (ORMC), a trauma surgeon described his experience providing care to injured patients who arrived in minutes, sometimes carried in on foot. With the threat of an active shooter and a surge of critically injured patients arriving without notice, the hospital's resources were quickly stretched to the limit.

\section{RESULTS}

We identified five themes common to all MCE responses. A summary of these themes can be found in box 1 and are described as follows:

\section{Assume non-traditional duties}

Delegation of tasks is key to maintaining quality care during a surge and returning to normal functions promptly. When resources are stretched thin, delegation may require assigning personnel to tasks that are outside the scope of their typical duties. In Mogadishu, more than 200 casualties arrived at the hospital during a time when staffing was already short due to a reduction of hospital personnel. As such, administrative nurses assumed clinical duties and medics moved from the prehospital to the inpatient setting to assist with patient care. In OPF, non-medical personnel assisted with patient movement and stocking supplies. Physicians applied their skills in non-traditional roles, such as the urologist who served as an operative assistant to the trauma surgeon and performed wound care duties. At Bagram, when the initial surge ended, trauma surgeons cleaned floors and administrative staff rounded to identify patients ready for discharge. In Baltimore, administrative assistants functioned as communication liaisons during the riots. Flexibility in assignments and the willingness of staff to perform whatever tasks were necessary, regardless of their usual duties, were noted by all panelists as essential components of MCE management.

Make and maintain clinical capacity by any means necessary To make the most of limited clinical capacity, all speakers emphasized the importance of canceling non-essential operations, promptly discharging eligible patients, and repurposing existing spaces into extended patient care areas. Outdoor areas were used for triage and treatment when additional emergency room space was required. To expand the capabilities of caring for those with critical injuries, rooms in the emergency department and/or postanesthesia care unit were used as additional intensive care unit (ICU) beds. During OPF, a pulmonary critical care intensivist was assigned as the triage officer to facilitate allocation and utilization of these impromptu ICU beds. In Baltimore extra equipment and supplies were mobilized from throughout the hospital and prehospital areas to create extra ICU areas. Anticipating the need for delayed second-look operations was essential. In Orlando, two operating rooms were set aside the following day for such operations. Discharge teams were assembled in Iraq, Baltimore, and San Francisco to facilitate and expedite patient throughput. Anticipating the need for physical therapy and rehabilitation assessment needs allowed San Francisco to plan for additional staffing and to facilitate

Box 1 Common themes identified in responses to military and civilian mass casualty events as described by the panelists

Assume non-traditional duties.

- Make space by any means necessary.

Revisit, review, retriage.

- Plan to deal with the media.

Take care of hospital staff. 
early postdischarge needs planning. When able, some hospitals diverted non-MCE-related patients to other medical centers.

\section{Revisit, review, retriage}

In the midst of surge, there is a huge workload with arrival of the initial wave of casualties. The focus of patient care is on immediate lifesaving interventions, which frequently means non-urgent details, documentation, and careful tertiary examinations are initially lacking. The team in OPF identified the need to revisit initial decisions, avoid assumptions, and not take anything for granted. Reviewing and repeating imaging was required to ensure nothing was missed by hasty initial readings or incomplete initial imaging. With large numbers of patients and especially with unusual mechanisms such as a plane crash, liberal use of imaging should be encouraged. ${ }^{5}$ Consolidating documentation and completing details that were missing were helpful to establish continuity as care continued forward. Repeated head to toe examinations, including examination of tympanic membranes and teeth, revealed initially missed injuries. Searching for retained objects in previously closed wounds and ensuring that hastily closed incisions were revised so that traumatic wounds were washed and closed in layers were done within the first 48 hours. Changing lines placed emergently, placing feed tubes, and assessing venous thromboembolism risk were then completed to ensure quality care measures were met that might have been missed during the MCE surge. This strategy was essential to ensuring all 243 patients treated at the MGH after the Boston bombing left the hospital alive. ${ }^{6}$ In one case, review of a chest $\mathrm{X}$-ray obtained on primary survey revealed fragments overlying the cardiac silhouette that had initially been missed. Careful interval review of all images initially read during the surge allowed this patient to receive potentially lifesaving care.

\section{Plan to deal with the media}

Particularly when the MCE took place on US soil, engaging with media was mentioned as a complicating factor in providing crisis patient care. In San Francisco and Orlando, hundreds of well-wishers, family members, and media arrived early after reports of the MCE hit the news. In Orlando and Baltimore, prominent politicians and celebrities arrived while patients care needs were still surging. These distractions can make caring for patients difficult and can distort public perceptions and violate patient confidentiality if not handled well. In San Francisco, the hospital leadership established regular conferences to engage with the press, created an official website, set up a call center with a hotline, and designated a separate family gathering area to help maintain control of what could otherwise have been a chaotic exchange of information. Regardless of the MCE, panelists emphasized ensuring a unified hospital message and hospital staff guidance of how to handle potential impromptu interactions with the media. Finally, talking first to patient families was essential to ensure information regarding their loved ones was conveyed from the hospital rather than through media outlets.

\section{Take care of hospital staff}

All the panelists emphasized taking care of medical staff as an essential part of maintaining quality patient care and being able to return to normal functions after an MCE. The physical and emotional toll of caring for injured patients in a crisis can drive healthcare workers to exhaustion. Thirty percent of the surgical residents who served at the ORMC during the Pulse Night Club Shooting experienced burnout, major depression, or post-traumatic stress disorder (PTSD) lasting 6 months after the crisis had ended. ${ }^{7}$ Similar instances of PTSD and fatigue were identified in Baltimore and were familiar concerns during the military MCEs. In instances in which the hospital staff were separated from their families and unable to return home, care providers faced additional stressors. The need to maintain a team fresh for assuming clinical duties meant forcing staff to sleep, eat, and rest even when they may be motivated to keep working. This fact held true for team leaders, including the panelists themselves, who found it difficult but necessary to designate and adhere to personal time limits and to delegate leadership responsibilities to others. Finally, ensuring the health and safety of personnel meant starting infectious disease testing and prophylaxis as necessary as needle sticks and exposure to blood and body fluids were ubiquitous. The ORMC encouraged early psychological counseling for all staff who participated in caring for patients during the MCE.

\section{CONCLUSIONS}

Unfortunately, many medical centers have dealt with MCEs in recent years, allowing our medical response to these crises to improve with experience. Collaboration between military and civilian physicians with experience in treating victims of mass violence is an important step toward ensuring preparedness for the next MCE. Having an idea of what to expect and some strategies to mitigate the challenges may hopefully help others when they are faced with dealing with similar tragedies.

Contributors RMR and JMG contributed equally to this article and should be considered joint first authors. RMR and JMG: concept, data collection and analysis, and article draft and revision. JBH, WD, JB, DRK, MMK, TMS, and MLC: data collection, analysis and article revision. RF: concept, data analysis, and article revision.

Funding The authors have not declared a specific grant for this research from any funding agency in the public, commercial or not-for-profit sectors.

Competing interests None declared.

Patient consent Not required.

Provenance and peer review Not commissioned; externally peer reviewed.

Open access This is an open access article distributed in accordance with the Creative Commons Attribution Non Commercial (CC BY-NC 4.0) license, which permits others to distribute, remix, adapt, build upon this work non-commercially, and license their derivative works on different terms, provided the original work is properly cited, appropriate credit is given, any changes made indicated, and the use is non-commercial. See: http://creativecommons.org/licenses/by-nc/4.0

\section{REFERENCES}

1. Blackbourne LH, Baer DG, Eastridge BJ, Kheirabadi B, Bagley S, Kragh JF, Cap AP, Dubick MA, Morrison JJ, Midwinter MJ, et al. Military medical revolution: prehospital combat casualty care. J Trauma Acute Care Surg 2012;73(6 Suppl 5):S372-7.

2. FEMA. Historic disaster response to hurricane harvey in Texas. Release Number: HQ-17133. Washington, DC, 2017

3. SAILOR C. This is not a drill: Military first on scene at Amtrak train derailment. Tacoma, WA: The News Tribune, 2017.

4. Mabry RL, Holcomb JB, Baker AM, Cloonan CC, Uhorchak JM, Perkins DE, Canfield AJ, Hagmann JH. United states army rangers in somalia: an analysis of combat casualties on an urban battlefield. J Trauma 2000:49:515-29.

5. Campion EM, Juillard C, Knudson MM, Dicker R, Cohen MJ, Mackersie R, Campbell AR, Callcut RA. Reconsidering the resources needed for multiple casualty events: lessons learned from the crash of asiana airlines flight 214. JAMA Surg 2016;151:512-7.

6. King DR, Larentzakis A, Ramly EP. Tourniquet use at the boston marathon bombing: lost in translation. J Trauma Acute Care Surg 2015;78:594-9.

7. Havron WS, Safcsak K, Corsa J, Loudon A, Cheatham ML. Psychological effect of a mass casualty event on general surgery residents. J Surg Educ 2017;74:e74-e80. 